\title{
Whipping Effect Model of High-rise Building and Corresponding Analysis
}

\author{
HE Ziqi $^{1}$, FAN Fei ${ }^{2}$, JIN Man ${ }^{3}$ \\ ${ }^{1}$ School of Civil Engineering and Architecture of Henan University, Kaifeng 475000, Henan, China
}

Keywords: High-rise Building; Whipping Effect; Aseismicity; Bending Moment

\begin{abstract}
When the building facade has unevenly distributed rigidity and the top thereof has protrusions or the facade rigidity is suddenly changed, the building top can easily have significantly increased amplitude and horizontal displacement under the action of earthquake. The above phenomenon is called whipping effect which is unfavorable for the stress, displacement and deformation of the structure top, so the whipping effect is particularly obvious in the aseismicity of the high-rise building. To research the occurrence essence of the whipping effect and avoid the whipping effect, it is necessary to firstly introduce the whipping effect and then analyze the difference between the whipping effect and the cantilever construction according to the characteristics of statically indeterminate structure and determinate structure; afterwards, it is necessary to adopt the finite element computational analysis software for modeling to simulate the application of dead load, live load and seismic load onto the three different high-rise building structures in order to calculate maximum inter-floor displacement (angle), (acceleration) speed, shearing force and bending moment, analyze and compare the displacement, movement and stress thereof; finally, the following conclusion is obtained: to reduce the influence of the whipping effect on the high-rise building, the facade rigidity stress of the high-rise building shall be constant or evenly changed.
\end{abstract}

\section{Introduction}

When the whipping effect takes place in a practical project, the structure top will have obvious horizontal displacement and the people at the building top will feel the significant shaking of the building and accordingly have panic psychology; additionally, due to the combined action of the earthquake inertia force (shearing force) caused by the horizontal shaking of the building top, the bending moment (normal stress) caused by loads, torque, etc., the parapet wall of the roof and the floor filler wall will generate slant crack (caused by the main pulling stress inside the structure); severely, some parts of the structure top will suffer from shear failure and even collapse due to large horizontal displacement. Therefore, it is necessary to pay high attention to the influence of the whipping effect on the structure top. To research the occurrence essence of the whipping effect and avoid the whipping effect, it is necessary to firstly introduce the whipping effect and then analyze the difference between the whipping effect and the cantilever construction according to the characteristics of statically indeterminate structure and determinate structure; afterwards, it is necessary to adopt the finite element computational analysis software for modeling to simulate the application of dead load, live load and seismic load onto the three different high-rise building structures in order to calculate maximum inter-floor displacement (angle), (acceleration) speed, shearing force and bending moment, analyze and compare the displacement, movement and stress thereof; finally, the following conclusion is obtained: to reduce the influence of the whipping effect on the high-rise building, the facade rigidity stress of the high-rise building shall be constant or evenly changed[1]. 


\section{Computer Simulation Building Model}

The finite element computational analysis software is adopted for modeling to simulate the application of dead load, live load and seismic load onto the three different high-rise building structures in order to calculate maximum inter-floor displacement, maximum displacement angle, acceleration, speed, shearing force and bending moment, analyze and compare the displacement, movement and stress thereof. The facade change forms of the three 10-floor high-rise buildings with different structures are respectively as follows: the facade of model 1 is vertically evenly arranged; the facade of model 2 is upwards gradually reduced from the 8th floor to form a protrusion at the roof; the facade of model 3 is upwards suddenly changed from the 1st floor (the facade between the 2nd floor and the 10th floor is constant). The main modeling parameters are as follows: one underground floor (floor height: $4 \mathrm{~m}$ ) and nine over-ground floors (floor height: $3 \mathrm{~m}$ ) along the vertical direction; longitudinal column space: $5 \mathrm{~m} \times 10$, transverse column space: $5 \mathrm{~m} \times 2+$ $2 \mathrm{~m}+5 \mathrm{~m} \times 2$; column section dimension: $600 \mathrm{~mm} \times 600 \mathrm{~mm}$, girder section dimension: $300 \mathrm{~mm} \times 600 \mathrm{~mm}$, slab thickness: $150 \mathrm{~mm}$; standard value of floor dead load: $3.0 \mathrm{KN} / \mathrm{m} 2$, standard value of variable load: $2.0 \mathrm{KN} / \mathrm{m} 2[4]$, without considering the linear load action of the filler wall; site classification: II, seismic fortification intensity: 7 degrees, the 3rd group, designed basic seismic acceleration: $0.10 \mathrm{~g}$, structural anti-seismic grade: I; concrete strength of frame column: C30, concrete strength of girder and slab: C25; girder and floor slab reinforcement and main reinforcement: HRB400, girder and column stirrup: HPB300. The stereogram of the computer simulation building model is as shown in the following figure:

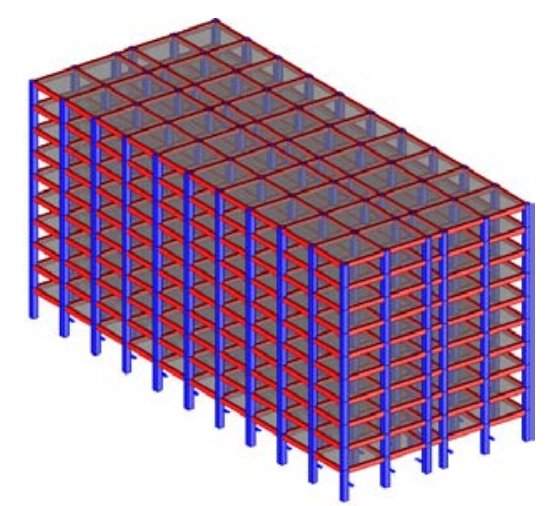

Fig.1. Model 1

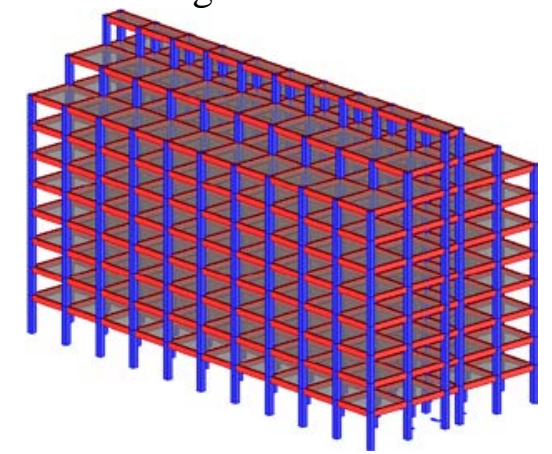

Fig.2. Model 2 


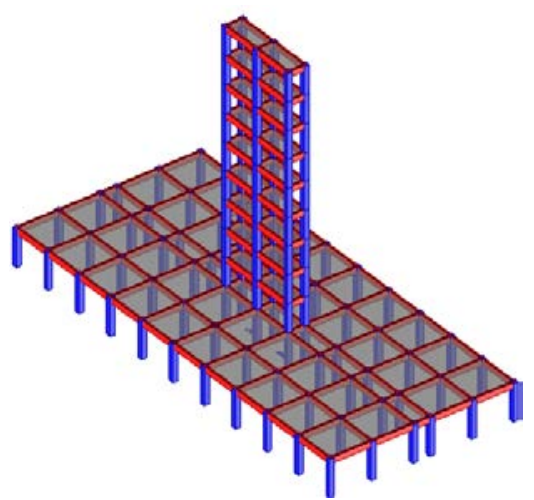

Fig.3. Model 3

\section{Calculation Results of Simulation Building Models and Contrastive Analysis Chart}

\section{Aseismic structure type}

The frame structure, the shear wall structure and the frame-shear wall structure have different load bearing modes. Therein, the frame structure belongs to flexible structure and the deformation thereof is in a shear mode, and has the characteristic that the inter-floor displacement is reduced along with the height increment, so the filler walls of the lower floors in the frame structure building have severe seismic hazard; the shear wall structure and the frame-shear wall structure belong to the rigid structure, and for the shear wall thereof has relatively strong lateral rigidity, the deformation thereof is approximately in a flexure mode, and such structure has the characteristic that the inter-floor displacement thereof is increased along with the height increment, so the filler walls of the upper floors in the shear wall structure and the frame-shear wall structure have severe seismic hazard. The flexible structure and the rigid structure are essentially different from each other. The lateral rigidity of the frame structure is much less than that of the shear wall structure or the frame-shear wall structure, and the frame structure mainly bears vertical loads, the shear wall and the frame-shear wall structure not only bear vertical loads, but also bear the horizontal loads caused by wind, earthquake, etc., so the structural stress analysis of the frame structure is different from that of the shear wall structure or the frame-shear wall structure.

\section{Calculation results of simulation building models}

RH1TG025 wave (artificial wave, characteristic period $=0.25$ s) is respectively adopted for the structural time-procedure analysis of the three 10-floor high-rise buildings with different structures. The calculation results of the models are as shown in the following tables. Therein, unit of maximum displacement: mm; unit of maximum displacement angel: rad; unit of speed: $\mathrm{mm} / \mathrm{s}$; unit of acceleration: $\mathrm{mm} / \mathrm{s} 2$; unit of floor shearing force: $\mathrm{KN}$; unit of floor bending moment: $\mathrm{KN} \cdot \mathrm{m}$. 
Tab.1. Computer simulation analysis result of model 1

Computer Simulation Analysis Result of Model 1

\begin{tabular}{c|c|c|c|c|c|c}
\hline Floor & $\begin{array}{c}\text { Maximum } \\
\text { Displacement }\end{array}$ & $\begin{array}{c}\text { Maximum } \\
\text { Displacement } \\
\text { Angle }\end{array}$ & Speed & Acceleration & $\begin{array}{c}\text { Floor } \\
\text { Shearing } \\
\text { Force }\end{array}$ & $\begin{array}{c}\text { Floor Bending } \\
\text { Moment }\end{array}$ \\
\hline 10 & 5.92 & $1 / 9999$ & 47.6 & 547 & 634 & 1902 \\
\hline 9 & 5.81 & $1 / 6810$ & 44.9 & 525 & 1032 & 4928 \\
\hline 8 & 5.62 & $1 / 5406$ & 41.1 & 465 & 1330 & 8794 \\
\hline 7 & 5.30 & $1 / 4817$ & 36.4 & 528 & 1508 & 13150 \\
\hline 6 & 4.81 & $1 / 4301$ & 30.1 & 517 & 1714 & 17862 \\
\hline 5 & 4.15 & $1 / 3820$ & 29.0 & 432 & 1974 & 22639 \\
\hline 4 & 3.36 & $1 / 3457$ & 28.6 & 478 & 2214 & 27856 \\
\hline 3 & 2.50 & $1 / 3338$ & 24.9 & 506 & 2338 & 33009 \\
\hline 2 & 1.62 & $1 / 3509$ & 18.3 & 539 & 2390 & 38009 \\
\hline 1 & 0.78 & $1 / 5097$ & 9.4 & 370 & 2559 & 47564 \\
\hline
\end{tabular}

Tab.2. Computer simulation analysis result of model 2

Computer Simulation Analysis Result of Model 2

\begin{tabular}{c|c|c|c|c|c|c}
\hline Floor & $\begin{array}{c}\text { Maximum } \\
\text { Displacement }\end{array}$ & $\begin{array}{c}\text { Maximum } \\
\text { Displacement } \\
\text { Angle }\end{array}$ & Speed & Acceleration & $\begin{array}{c}\text { Floor } \\
\text { Shearing } \\
\text { Force }\end{array}$ & $\begin{array}{c}\text { Floor Bending } \\
\text { Moment }\end{array}$ \\
\hline 10 & 5.68 & $1 / 8795$ & 50.1 & 998 & 181 & 543 \\
\hline 9 & 5.55 & $1 / 8267$ & 46.7 & 638 & 624 & 2416 \\
\hline 8 & 5.43 & $1 / 7226$ & 44.3 & 473 & 999 & 5414 \\
\hline 7 & 5.20 & $1 / 5869$ & 41.1 & 440 & 1231 & 8868 \\
\hline 6 & 4.81 & $1 / 4826$ & 36.4 & 462 & 1524 & 12717 \\
\hline 5 & 4.26 & $1 / 4044$ & 30.8 & 504 & 1860 & 17289 \\
\hline 4 & 3.58 & $1 / 3493$ & 23.5 & 529 & 2205 & 22792 \\
\hline 3 & 2.74 & $1 / 3184$ & 20.2 & 459 & 2484 & 28730 \\
\hline 2 & 1.80 & $1 / 3177$ & 16.9 & 420 & 2675 & 35531 \\
\hline 1 & 0.85 & $1 / 4685$ & 9.9 & 273 & 2757 & 45846 \\
\hline
\end{tabular}


Tab.3 Computer simulation analysis result of model 3

\begin{tabular}{c|c|c|c|c|c|c}
\hline \multicolumn{7}{c}{ Computer Simulation Analysis Result of Model 3 } \\
\hline Floor & $\begin{array}{c}\text { Maximum } \\
\text { Displacement }\end{array}$ & $\begin{array}{c}\text { Maximum } \\
\text { Displacement } \\
\text { Angle }\end{array}$ & Speed & Acceleration & $\begin{array}{c}\text { Floor } \\
\text { Shearing } \\
\text { Force }\end{array}$ & $\begin{array}{c}\text { Floor Bending } \\
\text { Moment }\end{array}$ \\
\hline 10 & 7.62 & $1 / 2748$ & 60.1 & 1370 & 55 & 166.9 \\
\hline 9 & 6.73 & $1 / 2594$ & 45.2 & 625 & 79 & 404 \\
\hline 8 & 5.78 & $1 / 2793$ & 39.7 & 650 & 69 & 613 \\
\hline 7 & 4.77 & $1 / 2805$ & 39.7 & 941 & 59 & 735 \\
\hline 6 & 3.73 & $1 / 2861$ & 35.0 & 769 & 70 & 764 \\
\hline 5 & 2.89 & $1 / 3126$ & 31.9 & 842 & 77 & 833 \\
\hline 4 & 2.11 & $1 / 3746$ & 29.5 & 1137 & 81 & 1002 \\
\hline 3 & 1.44 & $1 / 3923$ & 25.9 & 1173 & 117 & 1118 \\
\hline 2 & 0.70 & $1 / 4947$ & 16.9 & 742 & 144 & 1261 \\
\hline 1 & 0.20 & $1 / 9999$ & 7.7 & 453 & 782 & 3633 \\
\hline
\end{tabular}

Contrastive analysis chart for the calculation results of simulation building models

The contrastive analysis for the calculation results is as shown in the following figure:

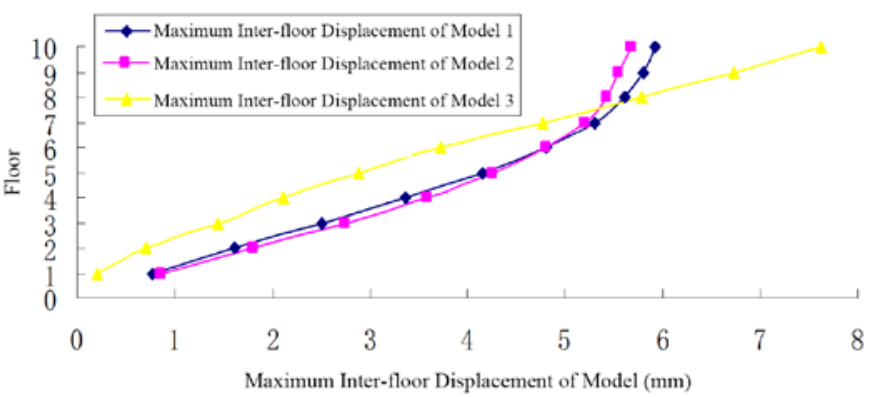

Fig.4. Maximum inter-floor displacement comparison of the models

\section{Conclusion}

In conclusion, in order to avoid the whipping effect in the building structure, it is necessary to pay high attention to the influence of the regularity of the plane, the facade and the vertical profile of the structure on the anti-seismic property and the economic rationality during the building design. Specifically, the lateral rigidity and the bearing capacity of the structure shall not be suddenly changed, so the structure with constant or similar lateral rigidity shall be preferably selected in order to ensure that even under the continuous reduction of the structural stress from top to bottom, the lateral rigidity of the structure is preferably gradually changed along with the rigidity of the structure to avoid plastic hinge. Since the structure bottom can have relatively large acting force due to the earthquake, shock reduction \& insulation measures can be taken for the structure bottom. In case protrusion needs to be set at the building top according to the actual requirements, it is necessary to increase the weight of the protrusion in order to prevent the protrusion from having the vibration frequency approximate to that of the earth and accordingly avoid the whipping effect generated due to the resonance of the two. The regular plane design scheme rather than the irregular plane design scheme shall be preferably adopted for the building structure design; for the complicated building structure with particularly irregular plane and facade, deformation joints can be set at proper positions according to the actual needs in order to form a number of relatively regular lateral load resistance structure units. The arrangement of deformation joints can increase concrete consumption, engineering cost, construction process and difficulty and prolong the construction period, but the reinforcement for the structure stress and unit area will be reduced; in case the horizontal displacement of the irregular structure cannot be determined, anti-collision walls 
can be set at the two sides of the deformation joint or energy dissipation and shock insulation measures can be taken for the structure to reduce seismic hazard. Additionally, the settlement joints, the seismic joints, the seismic joints, etc. in the building structure are usually integrated into the same deformation joint for design and construction in order to improve the integrity, the beauty and the simplicity of the structure.

\section{Reference}

[1] Li, Wubin, Johan Tordsson, and Erik Elmroth. "An aspect-oriented approach to consistency-preserving caching and compression of web service response messages." In Web Services (ICWS), 2010 IEEE International Conference on, pp. 526-533. IEEE, 2010.

[2] Y. Geng, J. He, K. Pahlavan, Modeling the Effect of Human Body on TOA Based Indoor Human Tracking[J], International Journal of Wireless Information Networks 20(4), 306-317

[3] Lv, Zhihan, and Tianyun Su. "3D seabed modeling and visualization on ubiquitous context." In SIGGRAPH Asia 2014 Posters, p. 33. ACM, 2014.

[4] Lv, Zhihan, Liangbing Feng, Shengzhong Feng, and Haibo Li. "Extending Touch-less Interaction on Vision Based Wearable Device." Virtual Reality (VR), 2015 iEEE. IEEE, 2015. 